\title{
EL NUEVO MARCO INSTITUCIONAL AMBIENTAL EN CHILE ${ }^{(.)}$
}

\author{
Alberto Olivares Gallardo \\ Becario de investigación \\ Universitat Rovira i Virgili \\ alberto.olivares@urv.cat
}

Recibido: 6 de mayo de 2010 / Aceptado: 7 de junio de 2010

RESUMEN: En esta nota se realizan algunos apuntes sobre la Ley 20417, de 26 de enero de 2010, que introduce un nuevo marco institucional ambiental para Chile. En este sentido, se hace una revisión histórica de la protección al medio ambiente en Chile, y la influencia que ha tenido la comunidad internacional en la construcción institucional ambiental en el país, hasta llegar al modelo que propone esta Ley.

RESUM: En aquesta nota es realitzen alguns apunts sobre la Llei 20417, de 26 de gener de 2010, que introdueix un nou marc institucional ambiental per a Xile. En aquest sentit, es fa una revisió històrica de la protecció al medi ambient a Xile, i la influència que ha tingut la comunitat internacional en la construcció institucional ambiental al país, fins arribar al model que proposa aquesta Llei.

\begin{abstract}
This study provides some notes on the Chilean Act 20417, January $26^{\text {th }}$ 2010, which introduced a new environmental institutional framework in Chile. In the context of this new regulation, the study goes over the history of environmental protection in Chile, and the influence which the international community has had on the construction of environmental institutions in this country up until the introduction of the new act.
\end{abstract}

\footnotetext{
(.) Este artículo ha sido elaborado en el marco del proyecto de investigación del Ministerio de Educación y Ciencia titulado "El derecho ambiental como modelo para la transformación de la actividad de los poderes públicos" (Referencia SEJ 2007/61972/JURI).
} 
PALABRAS CLAVE: Organización administrativa — protección del medio ambiente - Chile.

PARAULES CLAU: Organització administrativa — protecció del medi ambient — Xile.

KEYWORDS: Administrative organisation — environmental protection - Chile.

Sumario: I. Introducción. II. El intercambio de experiencias e instrumentos como elemento común del Derecho ambiental. III. El rol de la Constitución política de Chile en una primera etapa de protección del medio ambiente. IV. El sistema institucional ambiental de la Ley 19300/1994. V. La Ley 20417/ 2010: Un nuevo marco institucional ambiental para Chile. VI. A modo de conclusión. VII. Bibliografía. VIII. Legislación.

\section{INTRODUCCIÓN}

El ingreso de Chile a la OCDE ha significado, desde una perspectiva ambiental, el desarrollo de unas nuevas bases del sistema institucional ambiental, que brindan instituciones modernas de coordinación, ejecución y control, acorde al nuevo status de Chile, como país OCDE. La concreción de dicha idea, es realizada a través de la Ley 20417/2010, de 26 de enero, que crea el Ministerio, el Servicio de Evaluación Ambiental y la Superintendencia del Medio Ambiente.

Esta norma plantea una modernización del modelo institucional ambiental, a través de las siguientes ideas centrales: primero, la creación de nuevas instituciones que se constituyen en referentes del nuevo marco ambiental - el Ministerio, el Servicio de Evaluación y la Superintendencia del Medio Ambiente-; segundo, introduce importantes modificaciones a la Ley 19300/1994, sobre Bases Generales del Medio Ambiente, que permiten subsanar algunas debilidades del sistema de evaluación de impacto ambiental y resolver los problemas de coordinación entre las competencias sectoriales de los diversos órganos con atribuciones en materia ambiental; y tercero, incluye algunas nociones e instituciones actuales, como el principio ambiental de las "mejores técnicas disponibles" y la "evaluación ambiental estratégica", entre otros.

En este contexto, la presente nota pretende realizar algunos apuntes sobre la evolución del marco institucional ambiental de Chile, desde la introducción de una nueva visión 
de la protección a la naturaleza dado por la inclusión —en la Constitución de 1980 — de un derecho fundamental al medio ambiente libre de contaminación, el establecimiento de un marco institucional ambiental con la Ley 19300/1994 y su Reglamento ${ }^{2}$ (como segunda etapa de esta evolución); para concluir en el nuevo sistema institucional ambiental chileno introducido por la Ley 20417/2010. El hilo conductor de esta breve revisión del marco institucional ambiental de Chile, será la influencia de elementos exógenos - terceros estados y organismos internacionales- como elemento característico de la evolución del modelo ambiental chileno, desde sus cimientos hasta el sistema institucional ambiental que propone la Ley.

\section{EL INTERCAMBIO DE EXPERIENCIAS E INSTRUMENTOS COMO ELEMENTO COMÚN DEL DERECHO AMBIENTAL}

Históricamente, desde la irrupción de la protección de áreas de especial interés para el esparcimiento de las personas y la revolución que significó la National Environmental Policy Act en 1969 (que introdujo el sistema de evaluación ambiental), ha existido un transvase de instituciones y principios jurídicos entre las diversas legislaciones ambientales, que han uniformado en cierta manera el Derecho ambiental que se aplica en los países de influencia occidental. La comprensión del Derecho ambiental como “sistema de normas, principios, instituciones, prácticas operativas e ideologías jurídicas que regulan las relaciones entre los sistemas sociales y sus entornos naturales"3 explica en cierta manera esta afirmación. Las relaciones entre los sistemas sociales y sus entornos naturales han provocado problemas más o menos comunes, y la intervención del Derecho como instrumento social ha generado soluciones más o menos generales, que han sido estandarizadas en instrumentos, normas legales o modelos, y aplicadas con mayor o menor éxito en los diversos países. Existe una cierta filosofía común detrás de la regulación ambiental que se elabora por los estados y que permite un intercambio de experiencias e instrumentos que dan solución a problemas ambientales específicos y globales ${ }^{4}$.

\footnotetext{
${ }^{1}$ Ley 19300, sobre bases generales del medio ambiente, de 1994, modificada por la Ley 20173 de 2007.

${ }^{2}$ Reglamento del Sistema de Evaluación de Impacto Ambiental, Decreto Supremo 95, de 2001, que fijó el texto refundido del Decreto Supremo 30 de 1997.

${ }^{3}$ SERRANO, J., Principios de Derecho ambiental y ecología jurídica, Trotta, Madrid, 2007, p.29.

${ }^{4}$ Cfr. THORNTON, J., BECKWITH, S., Environmental law, Sweet \& Maxwell, London, 2004, p. 6.
} 
No obstante, esta eventual retroalimentación de legislación ambiental ha tenido, desde sus inicios, países y organismos internacionales que participan activamente en la creación y promoción de una ética ambiental, como Dinamarca, Suecia, Canadá, Alemania, Naciones Unidas, etc., y; por otra parte, estados que han ido incorporando de manera voluntaria o por compromisos internacionales la sensibilidad ambiental en sus sistemas institucionales, como por ejemplo Portugal, España, Brasil, Chile, entre otros. Es decir, este intercambio de experiencias e instrumentos de protección ambiental ha tenido un flujo horizontal entre estados con una sensibilidad ambiental equivalente, pero ha sido una relación más bien vertical entre estos países y organismos internacionales que promueven una relación amable del hombre con la naturaleza, con aquellos que han tardado mayor tiempo en incluir la protección del medio ambiente como una política pública. En este contexto, el caso chileno (y latinoamericano en general), se ha caracterizado por ser un Estado (como toda Latinoamérica) receptor de las propuestas generadas en el seno de otros estados y de organismos internacionales ${ }^{5}$.

Por consiguiente, si bien ha existido una integración — por el constituyente y legislador chileno- de las respuestas que ha dado el Derecho a la cuestión ambiental, provenientes de EEUU, Europa y organizaciones internacionales, no ha existido una reciprocidad de este enriquecimiento mutuo de las legislaciones provenientes de las diversas experiencias y soluciones planteadas por los Estados, en el sentido de que Latinoamérica ha generado escasas aportaciones al desarrollo de la legislación ambiental europea o estadounidense y se ha limitado a introducir en su Derecho, normas, instituciones, instrumentos y principios en los que ha apoyado sus construcciones jurídicas de protección del medio ambiente.

Como consecuencia, se ha generado una falta de correspondencia entre los principales problemas ambientales percibidos como tales por la comunidad (para el caso chileno) y la solución legislativa e institucional dada por el poder político, a través de la integración en el ordenamiento jurídico nacional de "soluciones ajenas", propuestas generalmente en compromisos internacionales con terceros estados $\mathrm{u}$ organismos internacionales, o auto impuestos por el propio Estado. Esta falta de conexión entre

\footnotetext{
${ }^{5}$ Es necesario señalar como excepciones a esta premisa, en el contexto latinoamericano, el caso de Costa Rica, que ha integrado una política general de protección del medio ambiente fundado en el amparo del patrimonio natural, y el caso de Brasil (aunque en este caso se trata de una política sectorial) que desde hace algunas décadas apostó claramente por el desarrollo del bioetanol como recurso energético de su parque automovilístico.
} 
percepción social del problema ambiental y la elaboración política de un sistema de protección ambiental fundado en instituciones e instrumentos provenientes de la práctica ambiental externa, trae como resultado una falta de legitimación de la legislación ambiental en Chile (y en Latinoamérica) por parte de la comunidad, situación que ha impedido construir una conciencia colectiva de protección de la naturaleza, necesaria para que el sistema de protección del medio ambiente que se otorga el país pueda arraigar en la sociedad y que, como consecuencia, integre la defensa del medio ambiente como soporte de la vida humana en una concepción profunda del Estado ambiental. De la misma forma, la ausencia de soluciones propias a los problemas ambientales, tanto los especiales como los globales, impide que emerja un punto de vista particular en el país, que permita involucrar a la comunidad con el sistema de protección al medio ambiente elaborado. Sobre estas ideas, en definitiva, se llevará a cabo la revisión de la evolución del modelo de protección ambiental chileno que se plantea en esta nota.

\section{EL ROL DE LA CONSTITUCIÓN POLÍTICA DE CHILE EN UNA PRIMERA ETAPA DE PROTECCIÓN DEL MEDIO AMBIENTE}

Es habitual que desde España y Europa en general se critique -y con justa razón- la poca relación que existe en Latinoamérica, entre lo establecido en sus constituciones y la realidad política, económica y social de la comunidad. Los diversos constituyentes latinoamericanos tienden a crear textos constitucionales extensos, pero que tienen poca aplicación práctica en la realidad política del país, existiendo, por ejemplo, amplios catálogos de derechos fundamentales, cuyo amparo ante el órgano jurisdiccional competente resulta complejo y poco eficaz.

El desarrollo de un sistema institucional en general, elaborado sobre las bases de un ordenamiento constitucional que interprete de manera efectiva la realidad social, política y económica de la comunidad en que está inmersa, permite no solo una convivencia armónica de las personas en sociedad, sino también la legitimación de éstas a los poderes, las instituciones y las normas que se desarrollen al amparo de la norma constitucional. En este sentido, de manera lúcida señaló el profesor Pablo Lucas Verdú: "El Derecho, y el Derecho Constitucional, en particular, tiene que ser vida, realidad efectiva para merecer la consideración de ordenamiento jurídico. Debe contrastar la Norma con la realidad de su aplicación para ser capaz de entenderlo tal como es y 
explicarlo en consecuencia. A esta inescindible relación entre la norma y la realidad me gusta referirme mediante la distinción entre tener Constitución y estar en ella que evoca en parte la que estableció hace ya muchos años Karl Loewenstein al diferenciar las constituciones normativas de las nominales" ${ }^{\prime 6}$.

La referencia a Loewenstein en este punto no es un simple ejercicio intelectual, sino que permite profundizar en lo que se desea explicar. El autor alemán realiza una clasificación ontológica de las constituciones en normativas y nominales, señalando que "el criterio de análisis ontológico radica en la concordancia de las normas constitucionales con la realidad del proceso del poder. Su punto de partida es la tesis de que una constitución escrita no funciona por sí misma una vez que haya sido adoptada por el pueblo, sino que una constitución es lo que los detentadores y destinatarios del poder hacen de ella en la práctica"7 . Estamos ante una constitución normativa cuando sus normas dominan el proceso político o, a la inversa, el proceso del poder se adapta a las normas de la constitución y se somete a ellas. En cambio, una constitución es calificada de nominal, cuando siendo jurídicamente válida, la dinámica del proceso político no se adapta a sus normas, carece- en consecuencia- de realidad existencial ${ }^{8}$.

En la actualidad, la casi totalidad de las constituciones de Latinoamérica poseen referencias expresas a la protección del medio ambiente, pero que no tienen recepción en el poder político y en la sociedad, que las hagan eficaces. No existe una verdadera simbiosis entre la constitución y la comunidad. Tenemos, por tanto, en el mundo latinoamericano -siguiendo la idea de Loewenstein-, constituciones nominales y referencias constitucionales a la protección del medio ambiente también nominales, que dificultan las construcciones doctrinaria y jurisprudencial constitucionales en torno a la protección de la naturaleza.

En el caso chileno, el constituyente de 1980 (no es objeto del presente texto legitimar o deslegitimar su actuación) siguió la corriente de las constituciones latinoamericanas de la época e incluyó una disposición relativa a la protección del medio ambiente en su artículo 19.8, en los siguientes términos: "La Constitución asegura a todas las personas

\footnotetext{
${ }^{6}$ ALZAGA VILlAMIL, O. (dir.), "Inauguración y exposiciones introductorias”, en Teoría y realidad constitucional, $\mathrm{n}^{\mathrm{o}} 21,1^{\mathrm{r}}$ semestre, 2008, p.91.

7 LOEWENSTEIN, K., Teoría de la Constitución (trad. de Gallego Anabitarte, Alfredo), Ariel, Barcelona, $1976^{2}$, p. 217.

${ }^{8}$ Op. cit., pp. 217-218.
} 
(...): El derecho a vivir en un medio ambiente libre de contaminación. Es deber del Estado velar para que este derecho no sea afectado y tutelar la preservación de la naturaleza. La Ley podrá establecer restricciones específicas al ejercicio de determinados derechos o libertades para proteger el medio ambiente".

Esta disposición está incorporada en el Capítulo III, "De los derechos y deberes constitucionales", encontrándose expresamente amparada por el recurso de protección (equivalente al recurso de amparo), de acuerdo a lo señalado por el artículo 20 de la Constitución: "Procederá, también, el recurso de protección en el caso del $\mathrm{N}^{0} 8^{\circ}$ del artículo 19, cuando el derecho a vivir en un medio ambiente libre de contaminación sea afectado por un acto $\mathrm{u}$ omisión ilegal imputable a una autoridad o persona determinada"9. Por tanto, hablamos de un derecho fundamental amparado por una acción cautelar de carácter constitucional frente a los menoscabos que pueden experimentar como consecuencia de acciones $\mathrm{u}$ omisiones ilegales o arbitrarias de la autoridad o de particulares ${ }^{10}$.

Sin embargo, la evolución del art. 19.8 de la Constitución de Chile se ha desligado de ese "tener constitución, sin llegar a vivir plenamente en ella", propio del constitucionalismo latinoamericano, y asumió -en una primera etapa de la protección del medio ambiente- un importante rol de defensa de los intereses ambientales de la comunidad. No solamente estableció un derecho de las personas a vivir en un medio ambiente libre de contaminación, sino que además, le confirió el carácter de derecho fundamental amparándolo con la acción que la propia Constitución establece para su protección. De la misma forma, la Corte Suprema asumió un rol activo en la evolución favorable de la disposición del artículo 19.8 de la Constitución, acogiendo numerosos recursos de protección para grandes causas ambientales del Chile de la época (la contaminación ambiental proveniente de la gran minería en el norte del país, el grave daño al equilibrio ecológico causado por la industria maderera del sur del país, y la saturación ambiental de las grandes ciudades, entre otros).

En este sentido, y contra lo que ha sido la regla general en el constitucionalismo ambiental latinoamericano, se pudo observar una fuerte jurisprudencia constitucional con sensibilidad ambiental, que permitió cimentar unas bases de protección del medio

\footnotetext{
${ }^{9}$ Constitución Política de Chile, art. 20.

${ }^{10}$ VERDUGO MARINKOVIC, M. y otros, Derecho Constitucional (tomo I), Editorial Jurídica de Chile, Santiago, $2005^{2}$, p. 338.
} 
ambiente de un nuevo modelo de protección que se desarrolló en Chile a partir de la Constitución de 1980, como consecuencia de la nueva sensibilidad ambiental que se respiraba desde Estocolmo 1972 y reforzada en Río 1992.

En este punto es necesario señalar un rasgo propio del recurso de protección establecido en la Constitución chilena que la distingue del recurso de amparo español, que podría en parte explicar la buena recepción que tuvo la protección constitucional de la naturaleza en la Corte Suprema. Mientras en el recurso de amparo la legitimación pasiva de la acción constitucional corresponde a "los poderes públicos del Estado, las Comunidades Autónomas y demás entes públicos de carácter territorial, corporativo o institucional, así como sus funcionarios o agentes" (Ley Orgánica del Tribunal Constitucional, art. 41.2), en el recurso de protección hay legitimación pasiva no solo de los poderes públicos, sino también de las personas, es decir, de los particulares, con la única exigencia de que sea "una persona determinada"11. Entonces, la posibilidad de que las personas pudieran actuar no solo contra el poder público, sino que también contra particulares que realicen actos que causen daño al medio ambiente, concedió a las personas un eficaz instrumento jurídico de protección contra los daños al medio ambiente causados por la gran industria que actuaba en el territorio.

Por otra parte, la inexistencia de un marco institucional ambiental, al momento de dictarse la Constitución de 1980, dio rienda suelta al constitucionalismo de la época y a la Corte Suprema en particular, para elaborar y desarrollar una importante doctrina constitucional de protección del medio ambiente — fundado en este artículo $19 \mathrm{~N}^{\circ} 8 \mathrm{de}$ la Constitución de Chile-, que llegó incluso a tener momentos sobresalientes con la resolución favorable a los intereses de la salud de la población y protección del medio ambiente — vía recurso de protección — en casos emblemáticos como los de: Forestal Trillium ${ }^{12}$; "Bórquez Muñoz" contra la Fundición de Paipote; o la conocida causa "Flores San Martín contra Codelco-Chile", por el vaciado de los relaves de cobre en el litoral de Chañaral ${ }^{13}$.

\footnotetext{
${ }^{11}$ Constitución Política de Chile, art. 20.

${ }^{12}$ Véase, BORDALÍ SALAMANCA, A., "Empresa forestal Trillium limitada", Revista de Derecho, vol. 8, núm. 1, 1997.

13 Véase, BERTELSEN REPETTO, R., "El recurso de protección y el derecho a vivir en un medio ambiente libre de contaminación. Examen de quince años de jurisprudencia", Revista Chilena de Derecho, vol. 25, núm. 1, 1998.
} 
No obstante, se trató de una actuación lúcida de la Corte Suprema para dar solución a grandes problemas ambientales en el país, en un momento histórico de introducción de la cuestión ambiental en Chile, ante la ausencia de otros instrumentos eficaces para la solución de estos problemas.

No se puede hablar de construcción de un modelo de protección ambiental que haya sido el resultado de un proceso de diálogo social, político y económico necesario para que exista una ineluctable complementación entre los problemas ambientales percibidos por la comunidad y las soluciones planteadas por el Poder político para esos problemas ambientales propios del país y de cada comunidad. Más bien, la Corte Suprema asumió un rol de válvula reguladora de los requerimientos sociales de carácter ambiental ante la ausencia de instrumentos jurídicos propios y especiales para la protección de la Naturaleza en cuanto soporte vital del hombre, valiéndose de un instrumento eficaz para paralizar la actividad depredadora de la gran industria, pero insuficiente para incentivar el diálogo social sobre el rol de la protección ambiental en el modelo de desarrollo que se construía en el país o crear una conciencia ambiental a nivel social, político y económico.

\section{EL SISTEMA INSTITUCIONAL AMBIENTAL DE LA LEY 19300/1994}

La Ley 19300, de 1994, sobre Bases Generales del Medio Ambiente ${ }^{14}$, integró la protección del medio ambiente en el debate político nacional. Si bien, es posible encontrar algunas normas en Chile de data anterior a esta época, se trata de legislación sectorial, sin una idea global de protección del medio ambiente, y donde el bien jurídico a proteger era principalmente la salud de la población humana y solo de manera incidental se podía encontrar referencia a la protección de la naturaleza.

Esta legislación ambiental, buscaba conceder al país un régimen jurídico especial de protección del medio ambiente, donde se establecía un modelo coordinador de todo el sector público, a través de la creación de la Comisión Nacional del Medio Ambiente (CONAMA), que tendría a su cargo la proposición de las directrices ambientales a desarrollar, así como el control de su cumplimiento ${ }^{15}$. También se elaboró un sistema de

\footnotetext{
${ }^{14}$ Ley 19300, modificada por la Ley 20173/2007, desarrollada por el Reglamento sobre el Sistema de Evaluación de Impacto Ambiental, establecido mediante Decreto Supremo 30 de 1997.

${ }^{15}$ Mensaje No 352-356, de la Presidenta de la República con el que inicia un proyecto de ley que crea el Ministerio, el Servicio de Evaluación Ambiental y la Superintendencia del medio ambiente, 5 de junio de
} 
evaluación de impacto ambiental (SEIA), al cual las actividades que alteraran de manera significativa el entorno debían someterse. Asimismo, hacía referencia a la promoción de la investigación, educación ambiental y participación, pero sin establecer mecanismos claros para concretar estas labores.

Esta institucionalidad ambiental propuesta en la Ley 19300 fue diseñada siguiendo el modelo de la "propuesta de Ley básica de protección ambiental y promoción del desarrollo sostenible" de 1993, elaborado para Latinoamérica por el Programa de las Naciones Unidas para el Medio Ambiente (PNUMA) ${ }^{16}$, que formulaba los criterios y normas básicas destinadas a regular la gestión ambiental del Estado y las acciones de los habitantes a fin de alcanzar los objetivos del desarrollo sostenible del país. De la misma forma, proponía el desarrollo de un sistema de evaluación ambiental, organizado en torno a dos niveles de control administrativo: la licencia ambiental y el estudio de impacto ambiental; promovía la educación y capacitación ambiental; incentivaba la elaboración de un régimen de beneficios e incentivos económicos, destinado a las empresas que colaboren con el desarrollo sostenible, y; planteaba la creación de una Comisión Nacional del Medio Ambiente, como órgano coordinador de las políticas ambientales. Por último, impulsaba la gestión de los recursos naturales renovables de conformidad a las exigencias de desarrollo sostenible.

La propuesta del PNUMA, fue implementada en gran parte por la Ley 19.300/1994 e inspiró el desarrollo del sistema institucional ambiental nacional, aunque de forma atenuada. Así, por ejemplo, no acogió la sugerencia de otorgar el rango de Ministro al Presidente de la Comisión Nacional del Medio Ambiente, como tampoco incorporó el delito ambiental dentro de la legislación penal, entre otros puntos esenciales de la proposición. Se puede observar, por tanto, que el desarrollo institucional chileno no obedeció a un requerimiento social producto de la interrelación de la comunidad con su entorno, sino que fue impulsado desde una práctica internacional -proveniente principalmente desde Europa y EEUU- teorizada y estandarizada, que sirvió de base para el impulso de una sensibilidad ambiental de los países latinoamericanos.

\footnotetext{
2008, p. 6. Recuperado el 30 de marzo de $2010 \quad$ de [http://web.derecho.uchile.cl/cda/cda/investigacion/tramitacion/BOLETIN\%20352$356 \% 20$ Ministerio $\% 20$ del $\% 20$ Medio\%20Ambiente\%20final.pdf].

16 PROGRAMA DE LAS NACIONES UNIDAS PARA EL MEDIO AMBIENTE, Propuesta de Ley básica de protección ambiental y promoción del desarrollo sostenible, Oficina Regional para América Latina y el Caribe, D.F. México, 1993.
} 
Por otra parte, el desarrollo de un marco institucional ambiental para Chile impulsado por la Ley 19300/1994 significó, en cierta medida, el decaimiento del ímpetu con que la Corte Suprema conocía y resolvía temas relativos a la protección del derecho fundamental del artículo 19.8 de la Constitución (derecho a vivir en un medio ambiente libre de contaminación). Se había creado un modelo ambiental que implantaba un procedimiento administrativo para la evaluación de las actividades que pudiesen incidir en el medio ambiente, que incorporaba una nueva técnica: la participación ciudadana, a fin de que la comunidad presentase las alegaciones que estimase pertinentes al proyecto que se estaba sometiendo al SEIA. Las principales consecuencias fueron, primero, la legitimación de aquellas actividades que se sometían a la evaluación que determinaba la Ley 19300 y eran aprobadas. Esto daba un aura de legitimidad a la actividad ante la comunidad, aún cuando los procesos de participación ciudadana no estaban lo suficientemente desplegados en la legislación ambiental, ni hubiese una concienciación ambiental desarrollada por la comunidad para participar activa y eficazmente en el SEIA, y; segundo, una disminución de la labor protectora de la Corte Suprema a través del conocimiento de los recursos de protección, ya que este "aura de legitimidad" que daba a la industria la aprobación de la evaluación ambiental trababa la acción constitucional, generando un nuevo estadio de la relación de la Corte Suprema con el recurso de amparo ambiental, ya que el sujeto pasivo pasó a ser sistemáticamente la CONAMA o la oficina regional de esta entidad, la Comisión regional del Medio Ambiente (COREMA) y sus resoluciones sobre las declaraciones de impacto y los estudios de impacto ambiental ${ }^{17}$.

Asimismo, el desarrollo de un marco institucional ambiental basado en un modelo propuesto por un organismo internacional, -Naciones Unidas a través de PNUMA-, integró un sistema de protección del medio ambiente en ausencia de un diálogo social destinado a identificar los problemas ambientales sustanciales de la comunidad. Si bien es cierto, cualquier avance en materia ambiental en el Chile de la época siempre fue positivo, se hizo patente en este nuevo estadio del modelo institucional de protección del medio ambiente el alejamiento entre las prioridades sociales y el modelo ambiental propuesto, a fin de permitir una sensibilidad ambiental política acorde a los requerimientos de la comunidad.

17 Véase, como ejemplos, los recursos de protección: "Benavides contra CONAMA" de 2000, "Valenzuela contra CONAMA de 2002; "Horvath y otros contra Conama" (Proyecto Río Cóndor); "Baraona y otros contra COREMA de la X región"; "Castillo contra COREMA de la X región". 
No se pretende señalar que la sociedad latinoamericana, y la chilena en particular, no tengan una sensibilidad hacia situaciones que pueden ser identificados como problemas ambientales. Más bien se quiere expresar que la falta de diálogo social y de participación ciudadana en el modelo ambiental propuesto por el Poder político, ha permitido la imposición de un sistema de protección del entorno diseñado, desde un primer momento, con aportaciones provenientes del exterior — sea organizaciones internacionales o regímenes jurídicos foráneos - y que no obedece a la percepción social del problema ambiental. Así, retomando el ejemplo dado antes, se desarrolló un sistema de evaluación ambiental que — en teoría - permite la participación ciudadana, sin que haya existido una educación previa y un crecimiento mutuo "realidad socialrealidad política" para que dicha participación sea informada, eficaz y garantizada. De la misma forma $-\mathrm{y}$ dando otro ejemplo-, se ha creado un modelo energético que incentiva las fuentes renovables y estudia la opción nuclear ${ }^{18}$, sin que se hayan solucionado temas como el tratamiento de residuos, salvo en unas pocas comunas con mayores recursos - situación que a su vez erosiona los cimientos de la igualdad en materia ambiental-, o se haya integrado la ordenación del territorio como eficaz instrumento de control de las actividades en el territorio.

El proceso de adecuación del ordenamiento jurídico a las preocupaciones ambientales de una sociedad, edificado sobre la base de la participación de la ciudadanía, legitima por la comunidad la actuación de los poderes públicos y, por tanto, desarrolla una visión particular del país sobre el problema ambiental y las soluciones -sean originales o adaptadas de otras realidades- responden de manera eficaz a la propia realidad según la constatación previa que se ha efectuado en el diálogo social y político. Hablamos de una participación que actúa como válvula, es decir, un concepto que funciona como valor regulador del flujo de corrientes vitales en el Derecho que permiten adecuar el ordenamiento a los procesos evolutivos de la vida política y social ${ }^{19}$.

Sin embargo, el proceso de integración de la preocupación ambiental al modelo de desarrollo que ha configurado Chile, se ha fraguado de forma inversa. Hay una constatación del poder político de que se deben introducir instrumentos de protección

\footnotetext{
18 Véase, Comisión Nacional de Energía (2008), Política energética: Nuevos lineamientos. Transformando la crisis energética en una oportunidad. Recuperado el 7 de junio de 2010, de [http://www.cne.cl/cnewww/export/sites/default/12_Utiles/banners/politica_energetica.pdf].

19 JORDANO FRAGA, J., La protección del derecho a un medio ambiente adecuado, Bosch, Barcelona, 1995, pp.190-191.
} 
del medio ambiente en el modelo político y jurídico nacional, como respuesta a propuestas externas, sea Estocolmo 1972, Río 1992, Acuerdo de libre comercio CanadáChile de 6 de diciembre de 1996, Banco Mundial, PNUMA a través del "Proyecto de Ley básica de protección ambiental y promoción del desarrollo sostenible" de 1993, OCDE mediante las "Evaluaciones del desempeño ambiental-Chile" de 2005, entre otros; e introducidas estas propuestas, se va articulando un modelo de protección ambiental, que posee características más o menos comunes con los demás países, pero que no necesariamente interpreta de manera fidedigna las reflexiones de la sociedad sobre el tema ambiental.

Retomando la idea de Loewenstein: "la cuestión fundamental sobre si se hará realidad la conformación específica del poder prevista constitucionalmente depende del medio social y político donde la constitución tiene que valer. Cuando se implanta, sin una previa educación política, una democracia constitucional plenamente articulada en un Estado [...], es casi un milagro si toma raíces inmediatamente" ${ }^{20}$. Adaptando esta idea al tema ambiental, la adopción de un modelo ambiental tomado de otras realidades, que responde a otras vivencias (o a ninguna, ya que en algunos casos provienen de laboratorios jurídicos), difícilmente tomará raíces en una comunidad que no ha visto concordancia entre la selección social del problema ambiental y la institucionalidad ambiental propuesta desde el poder público.

Según señala José Luis Serrano: “O los problemas ambientales son seleccionados como sociales, percibidos por la sociedad o, desde el interior de la sociedad, no existen, o si existen su existencia no es relevante" ${ }^{, 2}$. Esto se traduce en la falta de compromiso de la sociedad con el sistema jurídico ambiental elaborado por el poder político.

\section{LA LEY 20417 DE 2010: UN NUEVO MARCO INSTITUCIONAL AMBIENTAL PARA CHILE}

Tal como indica el mensaje de la Presidenta de la República en el proyecto de Ley que crea el Ministerio, el Servicio de Evaluación Ambiental y la Superintendencia del Medio Ambiente -actual Ley 20417/2010, de 26 de enero-, las sugerencias de la OCDE para el ingreso de Chile en calidad de país miembro incentivaron el desarrollo

\footnotetext{
${ }^{20}$ LOEWENSTEIN, Teoría... cit., p. 217.

${ }^{21}$ SERRANO, J., Principios de Derecho... cit., p. 14.
} 
normativo de la política ambiental que desembocó en esta norma legal que permite "iniciar una nueva etapa en nuestra política ambiental, de manera de modernizar el actual sistema y garantizar adecuadamente los derechos de todos los ciudadanos"22.

La evaluación del desempeño de Chile, presentada por la OCDE en 2005, expresa que la política ambiental chilena se ha construido sobre la base de las consideraciones hacia la salud humana y el comercio internacional, declaración que resalta la simpatía del poder político por la denominada "Constitución económica" en el país. Asimismo, estima que los desafíos ambientales de Chile, para disminuir la "brecha relativa a la convergencia con los estándares ambientales de los países $O C D E$ " son fundamentalmente: i) aplicar sus políticas ambientales de forma cabal y eficiente; ii) profundizar en la integración de las consideraciones ambientales en las decisiones económicas, sociales y sectoriales; y iii) fortalecer su cooperación ambiental internacional"23.

En este sucinto análisis de la OCDE, se puede observar de manera subyacente, primero, el diagnóstico de los principales puntos que se critican al sistema ambiental elaborado a Chile, esto es: la existencia de una política ambiental que se ha desarrollado teóricamente, pero que no se ha plasmado en la práctica de manera íntegra y que, como consecuencia, impide el despliegue de las instituciones ambientales propuestas en orden a elevar de manera real los estándares ambientales del país y, la falta de una conciencia ambiental de todos los sectores de la sociedad, que permita el desarrollo de un Estado que integre las consideraciones ambientales en su vida diaria. Segundo, lograr el compromiso de Chile en la cooperación internacional para los problemas ambientales globales, integrándolo de manera implícita a la postura nacida de los países industrializados en Río 1992, que promueven la acción efectiva de los Estados en desarrollo, ante la idea de la responsabilidad común. Finalmente, la OCDE elabora cincuenta y dos recomendaciones referidos al fortalecimiento de la institucionalidad ambiental, la gestión ambiental, la democracia ambiental y a la implementación de medidas ambientales de tipo sectorial en las áreas donde se presentan mayores falencias

\footnotetext{
${ }^{22}$ Mensaje $\mathrm{N}^{\mathrm{o}} 352-356 \ldots$ cit., p. 1.

${ }^{23}$ Vid. Organización de Cooperación y Desarrollo Económicos (2005, 24-26 de enero), Evaluaciones del desempeño ambiental,...cit., pp. 15 y 16.
} 
(aire, agua, diversidad biológica, integración de las consideraciones ambientales en las decisiones económicas -minería, silvicultura, acuicultura-, entre otros) ${ }^{24}$.

De esta forma, el nuevo marco institucional ambiental que inicia una "nueva etapa de la política ambiental chilena" 25 , no hace otra cosa que introducir gran parte de las recomendaciones que propone la OCDE a Chile, en el proceso de incorporación de éste a dicho organismo, como miembro.

En este sentido, la Ley 20417/2010 introduce algunas novedades al modelo institucional ambiental chileno sobre la base de tres pilares:

a) Crea un conjunto de instituciones que asumen la dirección y la coordinación de las políticas ambientales del país (el Ministerio del Medio Ambiente); la administración del sistema de evaluación ambiental (el Servicio de evaluación ambiental) y; la fiscalización del sistema, de las normas e instrumentos de protección ambiental (Superintendencia del Medio Ambiente).

El Ministerio, colabora con el Presidente de la República en el diseño y aplicación de políticas, planes y programas en materia ambiental (art. 69 de la Ley 19300/1994, modificada por la Ley 20417/2010). Destaca su labor como secretaría coordinadora y colaboradora con los ministerios sectoriales en la formulación de criterios ambientales en las diversas políticas y planes que se elaboren.

Asimismo, se crea el Consejo de Ministros para la Sustentabilidad, organismo multisectorial encargado de: proponer las políticas para el "manejo, uso y aprovechamiento sustentables de los recursos naturales renovables" (art. 71.a. de la Ley 19300/1994) y; configurar los criterios de "sustentabilidad que deben ser incorporados en la elaboración de políticas y procesos de planificación de los ministerios" (art. 71.b.). Resulta llamativo que este Consejo asuma la labor de "proponer al Presidente de la República la creación de las Áreas Protegidas del Estado, que incluye parques y

\footnotetext{
${ }^{24}$ Las sugerencias de la OCDE en materia ambiental, se expresan en un documento que contiene 52 recomendaciones, realizadas en el proceso de aceptación de Chile como miembro de esta organización, en: Organización de Cooperación y Desarrollo Económicos (2005, 24-26 de enero), Evaluaciones del desempeño ambiental. Chile. Recuperado el 9 de abril de 2010, de [http://146.155.48.139/gestioncostera/pdf/Chile/OCDE_EVALUACION_MEDIOAMBIENTAL.pdf].

${ }^{25}$ Vid. Mensaje de la Presidenta... cit. p.1.
} 
reservas marinas, así como los santuarios de la naturaleza y de las áreas marinas costeras protegidas de múltiples usos" (art. 71.c.) ${ }^{26}$.

En esta última función del artículo 71.c., del Consejo de Ministros para la Sustentabilidad, vuelve a observarse el fuerte conflicto que existe en Chile entre las políticas de orden económico con la política ambiental, por lo que conviene hacer alguna reflexión sobre el tema.

En general, la idea que evoca el conjunto de normas y principios que puede incluirse en la denominación general Derecho ambiental dentro de un ordenamiento jurídico nacional, expresa una idea reciente en la historia jurídica de la sociedad: la regulación del conflicto "progreso económico- respeto al entorno". El primero, progreso económico, sustentado en la libertad empresarial, y el segundo, protección de la naturaleza, en cuanto sustento de la vida humana.

La idea decimonónica omnipresente del inalienable derecho de propiedad entra en conflicto desde el último tercio del siglo veinte con dos ideas fundamentales: la evolución del concepto de dignidad de la persona y la idea de protección del medio ambiente. Es decir, la evolución del concepto de dignidad humana exige al constituyente y a los poderes públicos garantizar un medio ambiente adecuado necesario para el desarrollo de una vida digna. De esta forma, señala Jordi Jaria i Manzano: "El Derecho ambiental constituye la expresión jurídica del compromiso entre desarrollo económico y tecnológico y la conservación del espacio físico como escenario de vida social, cuya configuración debe hacer posible el bienestar y la calidad de vida de los seres humanos. Este compromiso supone la determinación del modelo de desarrollo del que se dota una determinada comunidad, que escoge el grado de riesgo que asume en su desarrollo económico y tecnológico persiguiendo justamente el bienestar y la calidad de vida en relación con el otro factor determinante para la consecución de dichos fines, esto es, el propio medio ambiente" ${ }^{27}$. En el mismo sentido, expresa José Luis Serrano: “Al fin y al cabo la problemática ambiental deriva de la relación entre la libertad de

\footnotetext{
${ }^{26}$ El Consejo de Ministros para la Sustentabilidad esta integrado por los Ministros de Medio Ambiente y Sustentabilidad (que lo preside); de Agricultura; de Hacienda; de Salud; de Economía, Fomento y Reconstrucción; de Energía; de Obras Públicas; de Vivienda y Urbanismo; de Transportes y Telecomunicaciones; de Minería; y de Planificación (art. 71 Ley 19300/1994).

${ }^{27}$ JARIA I MANZANO, J., "El fundamento constitucional de los derechos de participación en materia ambiental de medio ambiente y su desarrollo en la ley 27/2006", Pigrau Solé, A. (Dir.), Acceso a la información, participación pública y acceso a la justicia en materia de medio ambiente: diez años del Convenio de Aarhus, Atelier, Barcelona, 2008.
} 
contaminar (para prosperar) y el derecho a sobrevivir (y de hacerlo dentro de unos determinados estándares de calidad de vida) ${ }^{, 28}$. Chile, en cada proceso de modernización que realiza a su modelo institucional ambiental, no logra desligarse de la idea de que el sistema económico implantado jamás puede estar en entredicho.

Retomando el análisis de la Ley 20417/2010, se crea también el Servicio de Evaluación Ambiental, como servicio público, dependiente del Ministerio del Medio Ambiente, que asume la "administración del sistema de evaluación de impacto ambiental, así como la coordinación de los organismos del Estado involucrados en el mismo, para los efectos de obtener los permisos" (art. 8 parte final de la Ley 19300). Este Servicio se desconcentra territorialmente a través de las Direcciones regionales de evaluación ambiental. Asimismo, se crean, junto a estas Direcciones regionales, unas Comisiones de evaluación (artículo 86) integradas por el Intendente (que la preside), el Director regional del Servicio de Evaluación Ambiental y los Secretarios regionales ministeriales de las secretarías con incidencia en el medio ambiente (Medio ambiente, Salud, Economía, Energía, Transportes, Obras Públicas, etc.) que serán las encargadas de autorizar los proyectos y actividades sometidas al sistema de evaluación ambiental, en el ámbito regional ${ }^{29}$.

Finalmente, crea la Superintendencia del Medio Ambiente, como órgano encargado de la "fiscalización del permanente cumplimiento de las normas y condiciones sobre la base de las cuales se han aprobado o aceptado los estudios y declaraciones de impacto ambiental, de las medidas e instrumentos que establezcan los planes de prevención y de descontaminación, de las normas de calidad y emisión, así como de los diversos planes de manejos" (art. 64 de la Ley 19300/1994).

b) Un segundo pilar de los avances logrados por la Ley 20417/2010, lo conforman un conjunto de modificaciones que se hacen al modelo ambiental de la Ley 19300/1994, que lo perfeccionan y mejoran su funcionamiento. La revisión del modelo permitió diagnosticar las debilidades que presentaba: "las dificultades propias de una institución transversal en una Administración pública vertical; la incomprensión jurídica y de gestión del concepto de coordinación; la intervención de la autoridad política en cuestiones que son eminentemente de decisión técnica; las dificultades que ha tenido la

\footnotetext{
${ }^{28}$ SERRANO, J., Principios de Derecho Ambiental... cit., p. 21.

${ }^{29}$ A estas Comisiones, de carácter regional, la propia Ley 19300/1994 les asigna el nombre de "Comisión establecida en el artículo 86 o Comisión de evaluación" (Así se refiere, por ejemplo en los arts. 9 y 19).
} 
administración regional y local del sistema; la dispersión de la fiscalización; una gestión débil en materia ambiental; el desequilibrio de los instrumentos de gestión (mucho sistema de evaluación ambiental, pocas normas) y la dispersión de normas ambientales, de orden sectorial" ${ }^{\prime 3}$. En este ámbito, se reforma el SEIA, dándole celeridad al procedimiento administrativo, reduciendo algunos plazos y ampliando el catálogo de actividades sometidas a este Sistema. En primer lugar, la administración del SEIA pasa a manos del Servicio de Evaluación Ambiental, pero la decisión de las declaraciones de impacto y los estudios de impacto ambiental recae en la denominada "Comisión de evaluación" antes vista (art. 9 de la Ley 19300). En caso de proyectos que afecten a más de una región, la declaración de impacto o el estudio debe ser decidido por el Director ejecutivo del Servicio de evaluación ambiental. En segundo lugar, se elimina la posibilidad que tenía el titular del proyecto sometido a evaluación de impacto ambiental, de acompañar una póliza de seguro para cubrir el riesgo por daños al medio ambiente e iniciar sus proyectos conjuntamente con la tramitación de la evaluación de impacto. En su lugar, se concede facultad a la Comisión de evaluación para requerir a los organismos del Estado respectivos, para que emitan los permisos sectoriales o realicen los pronunciamientos que exige la ley, a fin de pronunciarse sobre el estudio de impacto en el plazo estipulado por el artículo 15 de la Ley 19300 (120 días). Asimismo, se establece un plazo límite de cuarenta días, para que la Comisión de evaluación dicte la resolución que declara que el estudio de impacto iniciado carece de información relevante o esencial para su evaluación y rechazar el proyecto. Transcurrido este plazo, el procedimiento debe continuar hasta finalizar su tramitación. En tercer lugar, promueve la coordinación entre la resolución favorable del proyecto sometido del SEIA con los otros permisos sectoriales necesarios para el funcionamiento del proyecto o actividad. Por ejemplo, impide a las Direcciones de obras municipales otorgar la recepción definitiva del proyecto o actividad sin que sea exhibida la resolución de calificación ambiental favorable (art. 25 bis, Ley 19300/1994).

Otro elemento sustancial, en la modificación del SEIA, es la reestructuración de la participación ciudadana en el procedimiento de evaluación ambiental. Así, el derecho a "imponerse del contenido del proyecto y del tenor de los documentos" (artículo 28) y "a formular observaciones al Estudio de impacto" (artículo 29), cuyos titulares en el anterior modelo eran "organizaciones ciudadanas con personalidad jurídica y personas

\footnotetext{
${ }^{30}$ Vid. Mensaje de la Presidenta... cit. p.7.
} 
naturales directamente afectadas", pasa a tener un titular más amplio "cualquier persona, natural o jurídica". Se elimina la exigencia de ser "directamente afectados", aumentando la posibilidad de fiscalización de la ciudadanía de los proyectos que pueden afectar el derecho a vivir en un medio ambiente libre de contaminación. Asimismo, el artículo 30 bis de la Ley faculta al Servicio de Evaluación Ambiental para decretar la realización de un proceso de participación ciudadana en las declaraciones de impacto ambiental, que en el antiguo sistema no estaba contemplado.

c) Finalmente, un tercer pilar de la reforma al sistema ambiental promulgada por la Ley 20417, es la integración de instituciones y principios de derecho ambiental que han ido surgiendo de la praxis internacional en la materia. Cabe destacar, la mención expresa del acceso a la información ambiental, que acerca al modelo ambiental chileno a los requerimientos del Principio 10 de la Declaración de Río de 1992. De esta forma, los artículos 31 bis, 31 ter y 31 quárter desarrollan el derecho de toda persona a acceder a la información de carácter ambiental que se encuentra en poder de la Administración, crean un Sistema nacional de información ambiental a cargo del Ministerio de Medio Ambiente, y garantiza este derecho con una acción especial. Por otra parte, incluye el principio de "las mejores técnicas disponibles" como criterio para determinar los valores o parámetros exigibles en las normas de emisión (art. 40 de la Ley 19300/1994). Finalmente, introduce la Evaluación ambiental estratégica, como "procedimiento realizado por el Ministerio sectorial respectivo, para que se incorporen las consideraciones del desarrollo sustentable, al proceso de formulación de las políticas y planes de carácter normativo general que tengan impacto sobre le medio ambiente o la sustentabilidad, de manera que ellas sean integradas en la dictación de la respectiva política o plan, y sus modificaciones sustanciales" (art. 2 letra i bis, Ley 19300). La decisión del sometimiento a evaluación ambiental estratégica de las políticas y planes recae en el Presidente de la República a proposición del Consejo de Ministros para la Sustentabilidad.

La conformación de un nuevo modelo institucional ambiental, ideado bajo la propuesta de la OCDE, ha comenzado a dar sus primeros pasos, estando pendiente la creación de los reglamentos que desarrollen la Ley y que desplieguen todos los efectos deseados por el poder político, a fin de poder observar los verdaderos alcances de la reforma planteada. Sin embargo, intenta expresar un real deseo de modernizar la Administración ambiental, integrando instituciones e instrumentos que han sido creados desde la 
práctica de países con mayor experiencia ambiental que Chile y que son promovidos desde foros internacionales reconocidos. Se insiste en la ausencia de la participación ciudadana, no en la resolución de proyectos y actividades con incidencia en el medio ambiente, que está contemplada en el SEIA, sino en la configuración de esta reforma ambiental. Acaso, con la nueva estructura de las instituciones ambientales que se plantea con la Ley 20417/2010, se desarrolle un diálogo social profundo que permita la participación de la comunidad en las futuras reformas al sistema institucional ambiental, que forje, de una vez, una concienciación ambiental de la ciudadanía necesaria para el éxito de las políticas ambientales que se plantean desde la Administración.

Finalmente, es necesario reflexionar que el Derecho ambiental que se impone en Chile (y en varios países latinoamericanos), fundado en la absorción de conceptos, instituciones e instrumentos propuestos por organizaciones internacionales y otros estados, conlleva la orientación o reestructuración de los ordenamientos jurídicos nacionales hacia modelos, estructuras económicas o fenómenos jurídicos que facilitan la introducción de la idea de la globalización, que promueve la economía global y la eliminación de trabas al funcionamiento del mercado y al flujo de capitales. De esta forma se proponen estructuras ambientales globales, que permitan el mejor funcionamiento del mercado. Desde esta visión, la desidia ambiental de los países es vista como una barrera al funcionamiento del mercado global y la liberalización económica $^{31}$. En este contexto, el Derecho ambiental, se transforma en un instrumento modelador de conductas estatales y Ordenamientos jurídicos. En este orden de ideas, la integración que hace Chile de los modelos e instrumentos sugeridos por organizaciones internacionales y otros estados, en materia ambiental, significa también una reestructuración de su ordenamiento jurídico interno a todo nivel, especialmente económico.

\section{A MODO DE CONCLUSIÓN}

La concienciación ambiental debe ser una tarea que debe asumir el poder político, al igual que la promoción de la participación ciudadana ${ }^{32}$. Solo con una comunidad concienciada e informada se obtiene la participación ciudadana activa en la gestión

${ }^{31}$ Para profundizar en este tema, vid. CLARKSON, S. y WOOD, S., A Perilous Imbalance. The Globalization of Canadian Law and Governance, UBC Press, Vancouver, 2009.

${ }^{32}$ Vid. EMBRID IRUJO, A. (dir.), El derecho a un medio ambiente adecuado, Iustel, 2008, pp. 222-226. 
ambiental. Pero la Administración no solo debe garantizar la información, promover la participación ciudadana y crear mecanismos de acceso a la justicia en materia ambiental, en definitiva, crear conciencia ambiental. Es necesario -como consecuenciaque acoja en sus instituciones, los valores ambientales que afloren en esta sociedad concienciada, permitiendo el diálogo social en la formación del modelo de Estado que asume obligaciones ambientales en el ámbito nacional e internacional.

El desarrollo de un Derecho ambiental en Chile, y de un marco institucional ambiental como la que se propone en la Ley 20417 de 2010, no solo debe proponer el sometimiento de la actividad económica a determinados estándares ambientales, o la creación de un órgano de alta Administración para coordinar las diversas políticas ambientales de carácter sectorial; en eso consiste solo la mitad de la tarea de la evolución hacia un Estado que promueva el desarrollo sostenible. También es necesario, el fomento — en la misma medida - de instrumentos que permitan un aumento de la calidad de vida de las personas. Un Estado democrático moderno debe promover también la igualdad ambiental. Los ciudadanos que viven en comunas populosas deben tener una calidad de vida equivalente a aquellos ciudadanos que viven en comunas con mayores recursos ${ }^{33}$.

La promoción del aumento de la calidad de vida de la comunidad, fundado en la dignidad humana, debe ser una orientación de toda la Política ambiental, del marco institucional ambiental y del Derecho ambiental como instrumento del Poder público.

Es necesario que la sociedad chilena observe la evolución del marco institucional ambiental no solo como un instrumento que limita -dentro de un modelo de Estado determinado, y en la medida de lo posible- la actividad económica del país para introducir parcelas de "sensibilidad ambiental". Es necesario que la ciudadanía perciba - y mucho mejor, participe activamente-, el modelo de protección ambiental que se elabora desde las instituciones ambientales como un importante sistema que garantiza la voluntad permanente del Estado de promover el aumento de la calidad de vida de la comunidad, y como consecuencia, elevar los estándares de protección de la dignidad humana de sus habitantes. Caso contrario, la sociedad simplemente no acusa recibo de

\footnotetext{
${ }^{33}$ Sobre la idea de justicia social que envuelve la protección del medio ambiente, CAHILL, Michael, The Environmental and Social Policy, Routledge, London, 2002, p.14. También, DOBSON, Andrew, Justice and the Environment. Conceptios of Environmental Sustainability and Dimensions of Social Justice, Oxford University Press, Oxford, 1998.
} 
esta reforma institucional, la siente lejana y los efectos deseados por la norma no se cumplen de manera eficaz.

\section{BIBLIOGRAFÍA}

ALZAGA VILLAMIL, O. (dir.), "Inauguración y exposiciones introductorias", en Teoría y realidad constitucional, $\mathrm{n}^{\mathrm{o}} 21,1^{\mathrm{r}}$ semestre, 2008.

BERTELSEN REPETTO, R., "El recurso de protección y el derecho a vivir en un medio ambiente libre de contaminación. Examen de quince años de jurisprudencia”, en Revista Chilena de Derecho, vol. 25, núm. 1, 1998.

BORDALÍ SALAMANCA, A., "Empresa forestal Trillium limitada", en Revista de Derecho, vol. 8 núm. 1, 1997.

CAHILL, Michael, The Environmental and Social Policy, Routledge, London, 2002.

CLARKSON, S. y WOOD, S., A Perilous Imbalance. The Globalization of Canadian Law and Governance, UBC Press, Vancouver, 2009.

Comisión Nacional de Energía (2008), Política energética: Nuevos lineamientos. Transformando la crisis energética en una oportunidad. Recuperado el 7 de junio de 2010 ,

[http://www.cne.cl/cnewww/export/sites/default/12_Utiles/banners/politica_energetica. pdf].

DOBSON, Andrew, Justice and the Environment. Conceptios of Environmental Sustainability and Dimensions of Social Justice, Oxford University Press, Oxford, 1998. EMBRID IRUJO, A. (dir.), El derecho a un medio ambiente adecuado, Iustel, 2008.

JAQUENOD DE ZSÖGÖN, S., Derecho Ambiental, Dykinson, Madrid, 2002.

JARIA I MANZANO, J., "El fundamento constitucional de los derechos de participación en materia ambiental de medio ambiente y su desarrollo en la ley 27/2006”, en Pigrau Solé, A. (dir.), Acceso a la información, participación pública y acceso a la justicia en materia de medio ambiente: diez años del Convenio de Aarhus, Atelier, Barcelona, 2008.

JORDANO FRAGA, J., La protección del derecho a un medio ambiente adecuado, Bosch, Barcelona, 1995. 
LOEWENSTEIN, K., Teoría de la Constitución (trad. de Gallego Anabitarte, Alfredo), Ariel, Barcelona, $1976^{2}$.

Mensaje $N^{\circ} 352-356$, de la Presidenta de la República con el que inicia un proyecto de ley que crea el Ministerio, el Servicio de Evaluación Ambiental y la Superintendencia del medio ambiente, 5 de junio de 2008, p. 6. Recuperado el 30 de marzo de 2010 de [http://web.derecho.uchile.cl/cda/cda/investigacion/tramitacion/BOLETIN\%20352356\%20Ministerio\%20del\%20Medio\%20Ambiente\%20final.pdf].

Organización de Cooperación y Desarrollo Económicos (2005, 24-26 de enero), Evaluaciones del desempeño ambiental. Chile. Recuperado el 9 de abril de 2010, de [http://146.155.48.139/gestioncostera/pdf/Chile/OCDE_EVALUACION_MEDIOAMB IENTAL.pdf].

PROGRAMA DE LAS NACIONES UNIDAS PARA EL MEDIO AMBIENTE, Propuesta de Ley básica de protección ambiental y promoción del desarrollo sostenible, Oficina Regional para América Latina y el Caribe, D.F. México, 1993.

THORNTON, J., BECKWITH, S., Environmental law, Sweet \& Maxwell, London, 2004.

SERRANO, J., Principios de Derecho ambiental y ecología jurídica, Trotta, Madrid, 2007.

VERDUGO MARINKOVIC, M. y otros, Derecho Constitucional (tomo I), Ed. Jurídica de Chile, Santiago, $2005^{2}$.

\section{LEGISLACIÓN}

Constitución Política de Chile de 1980.

Ley 19300/ 1994, de 1 de marzo, sobre bases generales del medio ambiente, modificada por las Leyes 20173/2007 y 20417/2010.

Reglamento del Sistema de Evaluación de Impacto Ambiental, Decreto Supremo 95/2001, de 7 de diciembre, que fijó el texto refundido del Decreto Supremo 30/1997.

Ley 20417/2010, de 12 de enero, que crea el Ministerio, el Servicio de Evaluación Ambiental y la Superintendencia del Medio Ambiente. 